\title{
Pesquisa
}

\section{VALORES HUMANOS EM UMA INSTITUIÇÃO EDUCACIONAL PÚBLICA}

\author{
Maria do Socorro Andrade Reis \\ Gislene Farias de Oliveira
}

\section{Introdução}

Em geral, a maioria dos autores concorda que, os Valores humanos são importantes e necessários a convivência social. Na escola, muito pouco se fala sobre a necessidade de um convívio mais harmonioso. O que muito se vê, são intervenções pontuais em casos de desarmonia entre alunos. É preciso acordar de uma educação técnica para uma educação mais calcada nos valores sociais. E a humanização das relações deve se iniciar na escola, envolvendo todos os níveis funcionais: professores, alunos e funcionários.

As pessoas são maleáveis, diferentes e estão sempre se reorganizando enquanto seres humanos em relação, por conta das próprias mudanças nos seus contextos.

Durante muitos anos, o ensino se transformou numa repetição de conteúdos, provocando uma absurda fragmentação de padrões educativos, por exemplo: essa formação cabe à família, tal formação (informação) compete à escola, como se os dois grandes núcleos sociais da vida do educando não se associassem nem se complementassem. O resultado dessa dicotomia é hoje o que se tem nas escolas: bulling, violência, desrespeito a figura do mestre (PALMA FILHO, 1997).

A degradação da família e a perda gradativa do papel e função da educação, perde-se qualitativamente o cumprimento dos papéis desses importantes pilares de sustentação da vida social de um ser humano. Nesse ponto, parece haver uma tendência a tornar insuportável a convivência com o outro.

Talvez esteja mais que na hora de se buscar um retorno dos valores humanos através de uma educação mais humanizada, prática essencial para uma sociedade organizada.

Os valores têm sido estudados na Filosofia, Sociologia, Antropologia e têm seu lugar na Psicologia (ROKEACH, 1973). Existem distintas teorias dos valores para explicar e descrever o comportamento humano (ROS, 2001). De acordo com Ferrer (1988), as contribuições mais valiosas foram fomentadas por Pat Duffy e Talcott Parsons, na década de 1950, quando a Psicologia despertava para o interesse pelos valores, à medida que tentava estudar a conduta humana. Contudo, em meados dos anos 1960 a ciência psicológica começou a se dedicar ao tema. Um teórico de grande importância foi Milton Rokeach, que através de Rokeach Value Survey procurou pela primeira vez medir cientificamente este construto com independência de outros (FERRER, 1988; ROS, 2001). 


\section{Teorias sobre os Valores Humanos}

Para Rokeach (1973) existem cinco pressupostos básicos para a compreensão da natureza dos valores humanos: (a) o número de valores que uma pessoa possui é relativamente pequeno; (b) todos os homens possuem os mesmos valores em graus diferentes; (c) os valores são organizados em sistemas de valores; (d) os antecedentes dos valores humanos podem ser encontrados na cultura, sociedade, instituições e na personalidade; e (e) os valores humanos serão manifestados em virtualmente todos os fenômenos que os cientistas sociais possam considerar como importantes de serem pesquisados.

Rokeach (1973) postulou um sistema de valores que se divide em terminais e instrumentais, os quais são operacionalizados através de duas listas de 18 valores cada uma, tendo sido selecionados depois de alguns anos de pesquisa. Em uma lista se encontram os valores terminais, representando estados finais de existência, entre eles, salvação, igualdade, vida confortável, felicidade etc. Em outra lista, encontram-se os valores instrumentais, que expressam uma série de adjetivos, os quais descrevem certos modos de conduta que são considerados preferíveis, como por exemplo, corajoso, honesto, ambicioso, responsável etc.

Daí resulta a classificação dos valores terminais como auto-centrados (foco intrapessoal) ou centrados na sociedade (foco interpessoal) e dos valores instrumentais como morais ou de competência. Os valores morais referem-se ao modo de comportar-se e não necessariamente incluem valores relacionados a estados finais de existência; tais valores, quando violados, trazem um sentimento de culpa de foco interpessoal, por exemplo, honesto, responsável, pois estão relacionados à moralidade. Quanto ao outro tipo de valor instrumental, no caso, aqueles que podem ser chamados de competência, o seu foco se centraliza mais no pessoal do que no interpessoal. Neste caso, os valores lógico e inteligente, por exemplo, conduzem a um estado de competência, de que se está agindo de forma adequada.

Schwartz (1994) observa que Rokeach não classificou adequadamente os conteúdos dos valores, limitando-se a distinguir apenas entre aqueles que são pessoais e os sociais ou entre os morais e os de competência. Schwartz define valor como "uma meta trans-situacional desejável, variando em importância, que serve como princípio-guia na vida de uma pessoa ou outra entidade social” (p. 21). Este autor propôs então uma tipologia de conteúdos diferentes, com dez tipos motivacionais ou de valores, a qual foi originada a partir de três requerimentos humanos universais: (1) necessidades dos indivíduos como organismos biológicos; (2) requerimento de interação social; e (3) requerimento de harmonia e bem-estar no grupo.

As maiores inovações da teoria proposta por este autor foram, de acordo com Chaves (2003): (a) seu caráter classificatório dos conteúdos dos valores, obedecendo a tipos motivacionais, e (b) a estruturação circular dos valores, que assume um caráter dinâmico. Apesar de ser um modelo bastante complexo, não possui uma base teórica sólida que fundamente a origem dos valores, e conta com uma medida muito extensa.

Provavelmente, na atualidade, seja Ronald Inglehart considerado o autor de maior peso no tema dos valores humanos nas Ciências Políticas (GOUVEIA, 1998). Inglehart (1991) entende que os valores não são apenas úteis para estudar as condutas dos indivíduos, mas são também bons indicadores do nível de vida de uma população, além de sua utilidade para conhecer os estilos e hábitos de uma sociedade e/ou cultura. Para tanto, propõe uma teoria sobre os valores humanos fundamentada na idéia de escassez e socialização. 
A partir da teoria da hierarquia das necessidades (MASLOW, 1954 / 1970), Inglehart define duas dimensões básicas através das quais pretende identificar as mudanças entre gerações e comparar as culturas nacionais: materialismo - que diz respeito à satisfação de necessidades mais básicas e de segurança, isto é, valores materiais, e pós-materialismo - que se origina a partir da satisfação materialista, desencadeando os valores espirituais.

Estas dimensões, ou propriamente pólos de uma mesma dimensão (materialismo vs. pós-materialismo) são consideradas no modelo que se pretende utilizar no presente estudo, a saber: o proposto por Gouveia (2003), o qual é recente e cuja convergência foi comprovada em relação ao proposto por Schwartz, sendo uma medida mais parcimoniosa e com estudos realizados no contexto paraibano. Este tem assegurado adequação dos seus parâmetros psicométricos (CHAVES, 2003; MAIA, 2000). Além do que, anteriormente a este modelo não havia outro que abarcasse tão amplamente a extensão dos valores humanos básicos como representando todas as necessidades humanas propostas por Maslow (1954/1970). Portanto, este modelo é descrito mais detalhadamente a seguir.

\section{Os Valores Humanos Básicos}

Tomando como base o conjunto de necessidades proposto por Abraham Maslow, Gouveia (1998, 2003) tem apresentado um modelo alternativo para a tipologia dos valores humanos, estipulando a existência de valores básicos, cujo conceito indica que são “categorias de orientação que são desejáveis, baseadas nas necessidades humanas e nas precondições para satisfazê-las, adotadas por atores sociais, podendo variar em sua magnitude e nos elementos que as constituem" (GOUVEIA, 2003, p. 433).

Esta tipologia de valores vem sofrendo alterações recentes, em função das evidências empíricas e seus aprimoramentos teóricos (GOUVEIA, 2003). Atualmente, os valores básicos se resumem a 24, tendo sido inicialmente proposto um conjunto de 22 (GOUVEIA, 1998). Foram incluídos os valores obediência e prazer. A seguir todos são sumariamente descritos:

01. Sobrevivência: refere-se às necessidades fisiológicas mais básicas do homem, como beber ou dormir, cuja privação duradoura resultaria letal. Este valor parece ter sua evidente importância como princípio-guia na vida de pessoas que são carentes de recursos básicos.

02. Sexual: representa a necessidade fisiológica que o organismo tem de sexo e constitui uma orientação padrão para as pessoas jovens ou que foram privadas ou são em geral privadas deste estímulo.

03. Prazer: corresponde à necessidade fisiológica que o organismo tem de satisfação, entendida em termos amplos (comer, beber, divertir-se etc.). Embora este valor esteja relacionado ao anterior, sua diferença consiste em não ter uma fonte única e definida de satisfação.

04. Estimulação: refere-se às necessidades fisiológicas de movimento, cuja novidade para estímulos é representada por este valor. Representa-o indicadores como participar em muitas atividades.

05. Emoção: este valor está relacionado com ter excitação e buscar experiências arriscadas. A questão básica aqui diz respeito a desfrutar do perigo e buscar aventuras. A diferença do valor anterior é que este está relacionado ao risco e o anterior diz respeito ao movimento. As pessoas que adotam este valor são menos conformadas com as regras sociais. 
06. Estabilidade pessoal: a necessidade de segurança é parcialmente representada por este valor. A orientação aqui se refere a ter uma vida organizada e planificada. As pessoas que se orientam por este valor procuram assegurar sua própria existência.

07. Saúde: trata-se de outro valor que representa a necessidade de segurança. As pessoas que se orientam por este valor se preocupam com sua saúde antes de tornar-se enfermas.

08. Religiosidade: refere-se a outro valor que representa a necessidade de segurança. As pessoas orientadas por este valor crêem em Deus como o salvador da humanidade e buscam cumprir a Sua vontade.

09. Apoio social: também representa a necessidade de segurança. Pode-se ter os seguintes elementos como seu conteúdo: obter ajuda quando a necessite e sentir que não se está só no mundo.

10. Ordem social: este valor fecha o quadro de valores relacionados à necessidade de segurança. Caracteriza-se em viver em um país ordenado e estruturado e ter um governo estável e eficaz.

11. Afetividade: refere-se à necessidade de amor e pertença. Diz respeito a ter uma relação de afeto profunda e duradoura e ter alguém para partilhar seus êxitos e fracassos. Este valor acentua as amizades íntimas, as relações familiares e trocas de carinhos, afetos, prazeres e tristezas.

12. Convivência: enquanto o anterior relaciona-se à ênfase na relação pessoa-pessoa, este se centra na dimensão pessoa-grupo. Os elementos de seu conteúdo referem-se a conviver diariamente com os vizinhos e formar parte de grupos sociais ou religiosos.

13. Éxito: a necessidade de estima é representada por este valor e pelos dois seguintes. Seu conteúdo destaca a idéia de ser prático e alcançar as metas auto-impostas. As pessoas que o adotam têm claro um ideal de triunfo, e tendem a se orientar nesta direção.

14. Prestígio: refere-se à importância que se atribui ao contexto social. Não se limita a ser aceito pelos demais, senão reconhecido publicamente.

15. Poder: define a noção de poder social (ter poder para influenciar aos demais e controlar as decisões) e autoridade (saber que é o chefe de uma equipe). Quem dá importância a este valor pode prescindir da noção de poder legitimamente constituído.

16. Maturidade: representada a necessidade de auto-realização. Trata-se de descrever um sentido de autosatisfação ou cumprimento como ser humano (desenvolver todas suas capacidades). A pessoa que o considera importante como um princípio-guia tende a apresentar uma orientação social que transcende a pessoa ou o grupo em concreto.

17. Autodireção: este valor e o próximo representam a pré-condição de liberdade para satisfazer as necessidades básicas. Sua especificidade radica em destacar uma condição da natureza humana: a liberdade (sentir-se livre para vestir como queira, estar livre para mover-se, ir e vir sem empecilhos). Adotar este valor implica em um certo reconhecimento da própria auto-suficiência.

18. Privacidade: relaciona-se mais com um estilo de vida e acentua a liberdade de ter um espaço privado, onde se mantêm separados diferentes aspectos da vida. As pessoas que adotam este valor não subestimam os outros, apenas reconhecem o benefício de ter seu próprio espaço.

19. Justiça social: representa a pré-condição de justiça para satisfazer as necessidades básicas, definindo condições mínimas entre as pessoas, como: lutar por uma menor diferença entre ricos e pobres ou permitir que cada pessoa seja tratada como alguém valioso. 
20. Honestidade: este valor representa a pré-condição honestidade para satisfazer as necessidades. Refere-se ao compromisso da pessoa frente aos demais, permitindo que se crie um contexto ótimo para as relações pessoais (atuar responsavelmente de acordo com a sua palavra e ser honesto e honrado).

21. Tradição: representa, junto com o valor seguinte, a pré-condição de disciplina no grupo ou na sociedade para satisfazer as necessidades humanas básicas. Trata-se de seguir os padrões morais seculares, favorecendo um mínimo de harmonia no âmbito social.

22. Obediência: destaca-se com este valor a importância de cumprir seus deveres e obrigações do dia a dia e respeitar aos seus pais e aos mais velhos. É uma questão de conduta do indivíduo, que deve assumir um papel e se conformar com a hierarquia social tradicionalmente imposta.

23. Conhecimento: as necessidades cognitivas são representadas por este valor. Tem um caráter extra-social, não compreendendo exatamente o interesse de obter benefícios pessoais. Pretende-se ter conhecimentos atuais sobre temas pouco conhecidos e tentar descobrir sempre coisas novas sobre o mundo.

24. Beleza: este valor representa as necessidades de estética. Compreende uma orientação global, cujos interesses não são muito delimitados quanto aos benefícios (ser capaz de apreciar o melhor da arte, música e literatura, e ir a museus ou exposições onde coisas belas podem ser vistas).

Os valores humanos são explicados através das funções a que servem, por isso, o modelo proposto por Gouveia (2003) é chamado de Modelo Funcional dos Valores Humanos, o que se deve a constatações empíricas da adequação de seis funções psicossociais que agregam os valores.

Assim como proposto acerca dos interesses profissionais, Gouveia (2004) afirma que os valores humanos também podem ser representados por um hexágono de maneira que as relações entre as suas funções são proporcionais à distancia entre as mesmas (ver Figura 2).

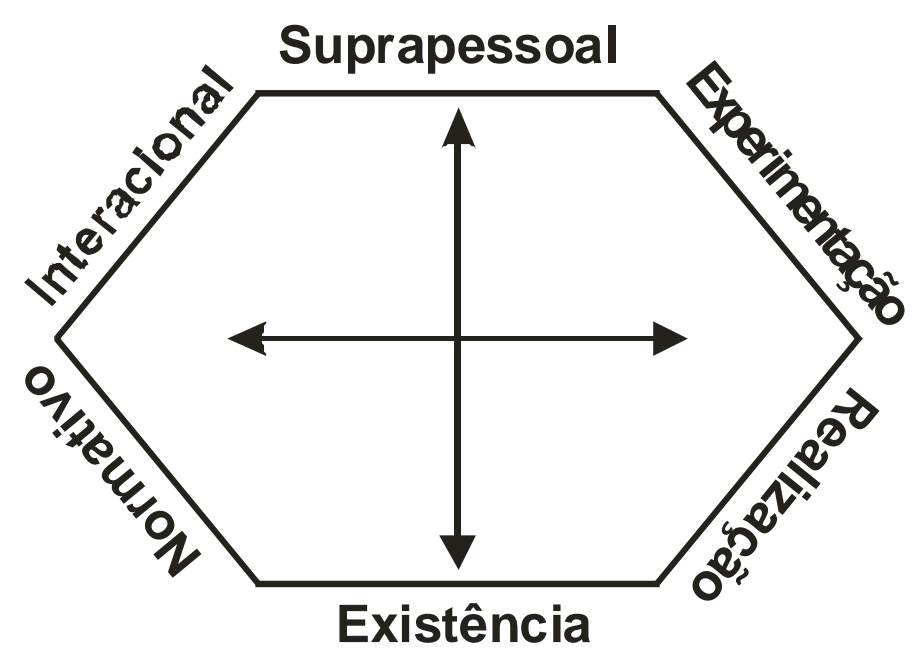

Figura 1. Modelo Funcional dos Valores Humanos.

As funções, com os respectivos valores que as representam, são: experimentação (emoção, estimulação, prazer e sexual), realização (autodireção, êxito, poder, prestígio e privacidade), existência (estabilidade pessoal, saúde e sobrevivência), suprapessoal (beleza, conhecimento, justiça social e maturidade), interacional (afetividade, apoio social, convivência e honestidade) e normativa (obediência, ordem social, religiosidade e 
tradição). Ademais, aparecem nos estudos realizados por Gouveia (1998, 2003) três grupos de valores representados por estas seis funções, a saber:

a) Valores pessoais. Quem assume este padrão de valores costuma manter relações pessoais de tipo contratual, geralmente com o fim de obter benefícios. Dá-se prioridade aos próprios benefícios ou às condições nas quais possam ser obtidos sem um marco de referência particular (papel social ou status). Na tipologia do Rokeach (1973), compreende os valores de foco intra-pessoal, centrados na própria pessoa. Dividem-se em: (1) valores de experimentação: descobrir e apreciar novos estímulos, enfrentar situações limite assim como buscar satisfação sexual compreendem aspectos centrais destes valores e (2) valores de realização: fazem parte do universo desejável humano a realização, o sentimento de ser importante e poderoso, ser uma pessoa com identidade e espaço próprio.

b) Valores centrais. Quem assume o padrão de valores centrais apresenta uma de duas dimensões: (1) valores suprapessoais: pólo pós-materialista no modelo, característico de alguém que logra seus objetivos independentemente de sua condição social ou grupo afiliativo, descrevendo pessoas maduras, com preocupações menos materiais, que não se limitam a características descritivas ou consideram traços específicos para começar uma relação ou proporcionar benefícios ou (2) valores de existência: pólo materialista em que se expressa uma preocupação de garantir a própria existência orgânica. Estes valores receberam esta denominação por serem compatíveis tanto com valores pessoais como com os sociais, embora sejam distintos destes ( GOUVEIA, 2003).

c) Valores sociais. Quem assume o padrão de valores sociais orienta-se em direção aos demais. Seu comportamento pode traduzir o desejo de se sentir considerado, assegurar sua aceitação e integração no seu grupo ou manter um nível indispensável de harmonia entre os diversos atores sociais de um contexto específico. Estes valores se dividem em dois conjuntos: (1) valores normativos: ênfase na vida social, na busca de estabilidade do grupo e no respeito pelos símbolos e padrões culturais que prevaleceram durante anos; estima-se a ordem acima de qualquer coisa e (2) valores interacionais: o sentido comum é o foco de atenção, que neste caso são os demais. Sua especificidade enquanto conjunto se fundamenta no interesse por se sentir querido, ter uma amizade verdadeira, uma vida social e apresentar comportamentos socialmente corretos.

A Figura 1 apresenta sucintamente este modelo de maneira que estão apresentados os dois eixos principais que norteiam os valores humanos: tipo de motivador (materialista e pós-materialista) e tipo de orientação (pessoal, social e central), os quais dão origem às seis funções psicossociais referidas anteriormente (GOUVEIA, 2004).

A seta na horizontal indica, à esquerda, valores sociais e, à direita, valores pessoais. De outro modo, a seta na vertical indica os valores centrais em sua dimensão pós-materialista (valores suprapessoais) e a dimensão materialista (valores de existência). Estes últimos são assumidos por pessoas que tendem a pensar em contextos específicos, ter uma visão pragmática da vida com pouca abertura. Trata-se de pessoas com idéias mais concretas, orientadas à hierarquização e à manutenção do status quo. Já aqueles valores pós-materialistas são adotados por pessoas que comumente não possuem um marco rígido de referência, são mais abertas ao novo, flexíveis e preocupadas em soluções mais igualitárias para os problemas sociais.

Na Figura 1 as relações entre as funções estão expressas pelas distâncias entre elas. É possível a compatibilidade de todos os valores, especialmente em pessoas com maior bem-estar subjetivo, todavia, tem se observado que algumas funções possuem maior relação com umas que com outras. Destarte, funções adjacentes são mais relacionadas que as funções alternadas ou opostas. Por exemplo, pessoas que dêem importância a 
valores suprapessoais, são mais prováveis a darem também importância a valores de experimentação ou interacionais do que aos demais (ver Gouveia, 2004).

Com o propósito de considerar os valores humanos na análise da relação entre a congruência vocacional e o bem-estar, faz-se mister tentar responder à questão: O que representa conceitualmente o bemestar e como este tem sido medido? No próximo capítulo se intenta responder a estas perguntas.

\section{Os Valores no Ambiente Educacional}

A globalização trouxe como paradigma a competitividade, o individualismo e isso impactou as pessoas de uma maneira extremamente negativa. Valores como a solidariedade, o respeito e a empatia ficaram quase obsoletos. Nas escolas, passou-se a ofertar uma educação, baseada numa formação inadequada, tipo "salve-se quem puder", junto com uma prática técnica e teórica desvinculada da realidade da natureza humana. Em outras situações, educadores podem não terem recebido uma educação com ênfase nos valores humanos ou não os utilizam nas suas relações sociais. Como então transmitir aquilo que não faz parte do cotidiano?

Culturalmente, o Brasil tem tradição da apologia ao individualismo, a lei de se levar vantagem em tudo. Em conversas com educadores, é comum a afirmativa de que a ética permeia as relações da classe, que o individualismo é uma das grandes barreiras a serem vencidas no coletivo das escolas. Se a palavra convence e o exemplo deixa a desejar. Assim, como transmitir aos alunos aquilo que não se pratica? É preciso que a escola e os educadores retomem o caminho de se construir, coletivamente uma base sólida para nossas relações, calcada numa educação de valores.

O objetivo geral deste estudo é analisar as prioridades valorativas dos professores e funcionários de uma Instituição Educacional Pública, para isso faz-se necessário, caracterizar a amostra, sócio-culturalmente e comparar as prioridades valorativas dos dois grupos, relacionando-as com as variáveis sexo, idade e religião.

A pesquisa propôs-se a um estudo transversal, quantitativo, correlacional, do tipo ex post facto. Considerou-se uma análise comparativa das variáveis (Valores humanos), no grupo de sujeitos considerados.

A amostra foi formada por professores e funcionários de uma Escola Pública. Trata-se de uma instituição de ensino localizada na zona urbana do município de Aiuaba, que oferece Educação Infantil e Ensino Fundamental de primeira a oitava séries.

A instituição selecionada neste estudo, deveu-se ao fato de haver uma aproximação com a pesquisadora e, porque abrange uma faixa em que os alunos já tem algum contato com a educação de valores humanos.

O instrumento de coleta de dados constou de um questionário com as seguintes partes:

a) Um Questionário contendo Valores Humanos Básicos de Gouveia (2003). O questionário doa VALORES HUMANOS BÁSICOS (GOUVEIA, 2003) é um instrumento, que apresenta 24 valores, tais como: Poder - ter poder para influenciar os outros e controlar decisões; ser o chefe de uma equipe, ou Privacidade - ter uma vida privada sem que os assuntos ou as pessoas da comunidade interfiram; ter sua própria moradia e receber nela só a quem deseja. O respondente deve indicar um grau de importância que este atribui a cada um dos valores, relativamente a sua vida, utilizando-se para isso de uma escala de sete pontos, que vai de $\mathbf{1}=$ Pouco Importante a 7 = Muito Importante. Em seguida, deve indicar o valor que considera o mais importante de todos enquanto um 
princípio-guia em sua vida, e depois indicar o valor que considera o menos importante de todos. Nestes dois casos, deve atribuir os escores $\mathbf{8}$ e $\mathbf{0}$, respectivamente. Tais escores substituem os graus de importância previamente definidos para os valores correspondentes (Anexo I). Segundo Maia (2000), esta medida apresenta parâmetros psicométricos adequados para a população brasileira. Gouveia (2003) observou que esta medida apresenta validade convergente com a que propõe S. H. Schwartz, e que os índices de bondade possuem ajustes aceitáveis para estrutura fatorial proposta: $\chi^{2} /$ g.l. $=2,67 ; G F I=0,91 ; A G F I=0,89$ e $R M S E A=0,05$.

b) Informações Sócio-Demográficas: Foi proposto um conjunto de perguntas visando caracterizar a amostra, a exemplo de idade, sexo, religião, escolaridade, estado civil, renda e profissão.

Os sujeitos foram contactados no próprio estabelecimento de ensino, em horário regular de atividades, onde responderam ao instrumento individualmente, em horário de disponibilidade e após serem esclarecidos do propósito do estudo..

\section{Análise dos Resultados}

\section{Caracterização do grupo investigado}

Compuseram o grupo de pesquisa, 31 sujeitos entre funcionários e professores do Centro Educacional Padre Pedro José, uma Instituição Educacional Pública no município de Aiuaba, no período de outubro de 2011, e, no intuito de melhor compreender os resultados obtidos, inicialmente, tratamos de apresentar informações que permitissem uma caracterização desses sujeitos.

As idades dos entrevistados variaram entre 17 e 60 anos, sendo 14 sujeitos (45,2\%) com idades entre 31 e 40 anos; 6 (19,3\%) com idades entre 41 e 50 anos. A idade média neste estabelecimento de ensino foi de aproximadamente 37 anos de idade. Portanto um estabelecimento com pessoas de uma faixa etária mais avançada, o que se pressupõe, pessoas mais maduras emocionalmente.

Com relação ao sexo, a amostra ficou assim representada: 23 sujeitos do sexo feminino, representando 74,2\% da amostra e 8 do sexo masculino, representando 25,8\% da amostra. Observa-se nesse caso uma maior participação das mulheres envolvidas com o trabalho na educação.

Para a caracterização socioeconômica, foi investigada também a autodenominação dos sujeitos quanto a sua classe social, os participante se autodenominaram, em sua maioria pertencentes a classe média baixa $(71,0 \%) ; 12.9 \%$ pertencentes à classe baixa e 12,9\% pertencentes a classe média. Apenas um sujeito $(3,2 \%)$ não informou nada neste item.

Segundo UNICEF (1990), o desafio mais importante dos anos 90 é a necessidade da retomada do perfil econômico e do desenvolvimento social nos países em desenvolvimento, e a solução conjunta dos perversos estragos da miséria e da fome, que continuam a afligir um número incontável de pessoas em todo o mundo. Como vulnerável segmento da sociedade humana, as crianças representam um interesse particular no 
crescimento econômico sustentado e na diminuição da pobreza, sem os quais não é possível assegurar-lhes bemestar.

Os aspectos socioeconômicos dos educadores também interferem no desenvolvimento da criança, assim como a pobreza destas igualmente estão relacionados com a estrutura familiar e social (MARTURANO, 1997).

A classe social dos professores e funcionários de uma instituição educacional é um fator importante para o desenvolvimento das crianças. O fator econômico é também um poderoso catalisador da existência de cuidados morais e de acompanhamento da conduta.

Com relação à profissão dos participantes, a amostra ficou assim distribuída: dezessete professores $(54,8 \%)$; sete auxiliares administrativos $(22,6 \%)$; dois coordenadores pedagógicos $(6,5 \%)$, duas merendeiras $(6,5 \%)$, um(a) diretor(a) 3,2\%); um vigia (3,2\%) e uma secretária (3,2\%).

Em sua maioria, os participantes são católicos $(80,7 \%)$, e, 16,1\% são evangélicos.

Investigamos, adicionalmente, a situação dos participantes quanto a escolaridade, conforme apresentamos a seguir.

Com relação à escolaridade pudemos observar que 9,7\% dos Participantes não completaram o Ensino Fundamental. Um não completou o ensino médio (3,2\%), 3 completaram o ensino médio $(9,7 \%), 2$ não completaram os estudos superiores $(6,4 \%)$ e a maioria completou os estudos superiores $(71,0 \%)$.

A escolarização dos participantes é fator importante no desenvolvimento moral e de valores das crianças. É na transmissão de informações e disseminação de hábito de conduta, que geralmente as crianças tomam seus pais e mestres como exemplo.

A escolaridade das pessoas que convivem com as crianças em idade escolar, estão associadas com diversas condições que constituem variáveis de risco para um desenvolvimento em termos de valores humanos mais adequados a uma convivência saudável para as crianças (CAETANO, 1992; SCHMITZ, 1999).

Os participantes são em sua maioria casados $(74,2 \%)$, o que, para uma instituição educacional, em que, geralmente, as crianças passam, pelo menos a metade do dia em convivência, pode significar o comprometimento do acompanhamento dos menores, inclusive, no que se refere ao cuidado com seus hábitos e atitudes.

Segundo Stefane (2000), uma educação baseada em valores humanos adquire especial relevo hoje em dia, quando sabemos que pais e mães têm pouco tempo disponível (por conta do trabalho fora do lar) ou que as crianças vivem parte do dia nas escolas.

\section{Priorização dos valores do grupo investigado.}

Para uma maior compreensão acerca da priorização dos Valores Humanos adotados pelos participantes, achamos necessário, identificar as prioridades valorativas dos participantes. Os dados estão dispostos na tabela a seguir. 
Tabela 08 - Distribuição dos resultados referentes as prioridades valorativas dos participantes. Aiuaba, 2011.

\begin{tabular}{|c|c|c|c|c|c|c|c|c|c|c|c|c|c|c|}
\hline \multirow[t]{2}{*}{$\begin{array}{l}\text { PRIORIDADES } \\
\text { VALORATIVAS }\end{array}$} & \multicolumn{2}{|c|}{$\begin{array}{c}\mathbf{1} \\
\text { Totalmente } \\
\text { não } \\
\text { importante }\end{array}$} & \multicolumn{2}{|c|}{$\begin{array}{c}\mathbf{2} \\
\text { Não impor- } \\
\text { tante }\end{array}$} & \multicolumn{2}{|c|}{$\begin{array}{c}\mathbf{3} \\
\text { Pouco } \\
\text { impor- } \\
\text { tante }\end{array}$} & \multicolumn{2}{|c|}{$\begin{array}{c}4 \\
\text { Mais ou } \\
\text { menos } \\
\text { impor- } \\
\text { tante } \\
\end{array}$} & \multicolumn{2}{|c|}{$\begin{array}{c}\mathbf{5} \\
\text { Impor- } \\
\text { tante }\end{array}$} & \multicolumn{2}{|c|}{$\begin{array}{c}\mathbf{6} \\
\text { Muito } \\
\text { impor- } \\
\text { tante }\end{array}$} & \multicolumn{2}{|c|}{$\begin{array}{c}7 \\
\text { Extrema } \\
\text {-mente } \\
\text { Impor- } \\
\text { tante }\end{array}$} \\
\hline & $\mathrm{n}$ & $\%$ & $\mathrm{n}$ & $\%$ & $\mathrm{n}$ & $\%$ & $\mathrm{n}$ & $\%$ & $\mathrm{n}$ & $\%$ & $\mathrm{n}$ & $\%$ & $\mathrm{n}$ & $\%$ \\
\hline 1. Justiça social & 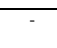 & - & 1 & 3,2 & & 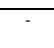 & 1 & 3,2 & 5 & 16,1 & 8 & 25,8 & 15 & 48,3 \\
\hline 2. Sexual & - & - & - & 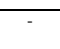 & 6 & 19,3 & 5 & 16,1 & 7 & 22,5 & 9 & 29,0 & 3 & 9,6 \\
\hline 3. Êxito & - & - & - & 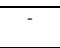 & 1 & 3,2 & 1 & 3,2 & 8 & 25,8 & 7 & 22,5 & 13 & 41,9 \\
\hline 4. Apoio social & - & - & - & - & 1 & 3,2 & - & - & 6 & 19,3 & 7 & 22,5 & 16 & 51,6 \\
\hline 5. Honestidade & - & & - & & $\cdot$ & - & & & 1 & 3,2 & 5 & 16,1 & 24 & 77,4 \\
\hline 6. Conhecimento & - & - & - & 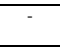 & - & - & 1 & 3,2 & 10 & 32,2 & 11 & 35,4 & 7 & 22,5 \\
\hline 7. Emoção & - & - & 5 & 16,1 & 7 & 22,5 & 12 & 38,7 & 3 & $\begin{array}{l}9,6 \\
\end{array}$ & 2 & 6,4 & - & - \\
\hline 8. Poder & - & - & 10 & 32,2 & 9 & 29,0 & 5 & 16,1 & 5 & 16,1 & - & $\cdots$ & - & - \\
\hline 9. Afetividade & - & - & - & - & - & - & 1 & 3,2 & 4 & 13,0 & 8 & 25,8 & 17 & 54,8 \\
\hline 10. Religiosidade & - & - & - & - & - & - & & & 2 & 6,4 & 10 & 32,2 & 18 & 58,0 \\
\hline 11. Autodireção & 1 & 3,2 & - & 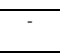 & 1 & 3,2 & 2 & 6,4 & 7 & 22,5 & 12 & 38,7 & 7 & 22,5 \\
\hline 12. Ordem social & - & - & 1 & 3,2 & 1 & 3,2 & 1 & 3,2 & 4 & 13,0 & 6 & 19,3 & 17 & 54,8 \\
\hline 13. Saúde & - & - & - & - & - & & 1 & 3,2 & - & - & 12 & & 17 & 54,8 \\
\hline 14. Prazer & - & - & 1 & 3,2 & 3 & 9,6 & 3 & 9,6 & 11 & 35,4 & 5 & 16,1 & 7 & 22,5 \\
\hline 15. Prestígio & - & - & 3 & 9,6 & 4 & 13,0 & 4 & 13,0 & 4 & & 10 & 32,2 & 5 & 16,1 \\
\hline 16. Obediência & - & - & - & - & - & - & - & - & 5 & 16,1 & 9 & 29,0 & 16 & 51,6 \\
\hline 17. Estabilidade pessoal & - & - & - & - & - & - & - & - & 6 & & 9 & 29,0 & 14 & 45,1 \\
\hline 18. Estimulação & - & - & 1 & 3,2 & 1 & 3,2 & 4 & 13,0 & 9 & 29,0 & 9 & 29,0 & ${ }^{6}$ & 19,3 \\
\hline 19. Convivência & - & - & - & & & & 3 & 9,6 & 12 & & 7 & 22,5 & 8 & 25,8 \\
\hline 20. Beleza & & & - & & 1 & 3,2 & 4 & 13,0 & 11 & 35,4 & 7 & 22,5 & 6 & 19,3 \\
\hline 21. Tradição & - & - & 2 & 6,4 & 1 & 3,2 & 5 & 16,1 & 8 & 25,8 & 12 & 38,7 & 2 & 6,4 \\
\hline 22. Sobrevivência & - & - & - & & - & - & - & - & 2 & 6,4 & 6 & 19,3 & 21 & 67,7 \\
\hline 23. Maturidade & - & - & - & - & 1 & 3,2 & - & - & 3 & & 9 & 29,0 & 17 & 54,8 \\
\hline 24. Privacidade & - & - & - & & - & - & 4 & 13,0 & 8 & 25,8 & 8 & 25,8 & 10 & 32,2 \\
\hline
\end{tabular}

A tabela 8 demonstrou que os dez valores considerados extremamente importantes foram: Honestidade (77,4\%); Sobrevivência (67,7\%); Religiosidade (58,0\%); Afetividade, Ordem social, Saúde e maturidade (54,8\%); Apoio social (51,6\%); Justiça social e Estabilidade pessoal $(45,1 \%)$.

Em seguida, tratamos de observar os valores considerados mais importantes pelos sujeitos da amostra. Os dados estão na tabela a seguir.

Dentre os quatro valores considerados MAIS IMPORTANTES pelos sujeitos de uma maneira geral estão: Honestidade (19,4\%), Religiosidade (19,4\%), Saúde (19,4\%), e Emoção (13,0\%). Em seguida a Justiça social $(9,6 \%)$, a Convivência $(6,4 \%)$ e a Sobrevivência $(3,2 \%)$.

Investigamos também os valores considerados MENOS IMPORTANTES pelos sujeitos.

Observa-se, a partir dos resultados, que os sujeitos consideraram MENOS IMPORTANTE o Poder (45,0\%), Sexual (19,4\%), alem de Êxito, Emoção e Tradição (6,4\%), cada um. Também foram considerados menos importantes o Apoio social (3,2\%), Autodireção (3,2\%), a beleza (3,2\%) e a Privacidade $(3,2 \%)$. 


\section{Considerações Finais}

Conclui-se aqui que a congruência pessoa-ambiente, que tem sido por muito tempo considerada como importante para a transmissão de valores, empiricamente se comprovou no contexto estudado. Observou-se uma valorização pelos sujeitos de valores básicos como a Honestidade, Saúde, Justiça social e convivência, bases para a vida em relação e para o desenvolvimento da Solidariedade. Estes valores foram considerados em detrimento do Poder, Sexual, Êxito e Tradição. Os valores humanos parecem seguir como construtos importantes a serem considerados na educação das crianças e adolescentes. Entretanto, outros estudos que controlem variáveis aqui não consideradas, em adição ao presente trabalho, conformem uma base teórica para entendimento de que aspectos poderiam ajudar na promoção de uma vida mais saudável, com maior bem-estar no ambiente educacional.

Esse estudo pretendeu ser mais um estudo no âmbito dos Valores Humanos, considerando-se, até que ponto professores e funcionários de uma instituição educacional consideram determinados valores humanos como princípios guia em suas vidas. Ela pode abrir campo para a realização de estudos futuros que complementem o conhecimento na área, tendo em vista a escassez de estudos dessa natureza no Brasil. Portanto, o objetivo aqui foi de ser um instrumento a mais na compreensão desse construto, não havendo pretensão conclusiva.

\section{Referências}

CAETANO, L. C., 1992. Aleitamento Materno: Fatores que Contribuem para a sua Prática. Dissertação de Mestrado, São Paulo: Escola Paulista de Medicina, Universidade Federal de São Paulo.

CHAVES, S. S. da S. Valores como preditores do bem-estar subjetivo. Dissertação de Mestrado. Departamento de Psicologia, Universidade Federal da Paraíba, João Pessoa, PB. (2003).

FERRER, J. G.. Valores humanos: Principales concepciones teóricas. Valencia, Espanha: NAU llibres. (1988) GOUVEIA, V. V. La naturaleza de los valores descriptores del individualismo y del colectivismo: Una comparación intra e intercultural. Tese de Doutorado. Faculdade de Psicologia, Universidade Complutense de Madri, Espanha. (1998).

. A natureza motivacional dos valores humanos: Uma nova tipologia. Estudos de Psicologia, 8, 431-443. (2003).

INGLEHART, R. (1991). El cambio cultural en las sociedades industriales avanzadas. Madri: Centro de Investigaciones Sociológicas / Siglo XXI Editores.

MAIA, L. Prioridades valorativas e desenvolvimento moral: Considerações acerca de uma teoria dos valores humanos. 2000 Dissertação (Mestrado em Psicologia Social). Universidade federal da Paraíba, João Pessoa, PB. 2000.

MASLOW, A.H. Motivation and personality. New York: Harper \& Row Publishers. (1954 / 1970). MARTURANO, E. M., 1999. Recursos no ambiente familiar e dificuldades de aprendizagem na escola.

Psicologia: Teoria e Pesquisa, 15: 135-142. 
PALMA FILHO, J. C. .Lei de Diretrizes e Bases da Educação Nacional - organização, apresentação e comentários. Cooperativa Técnico Educacional e SEE/SP, 1997. 58 p.

ROS, M. (2001). Psicología social de los valores: Una perspectiva histórica. Em M. Ros \& V. V. Gouveia (Orgs.),

Psicología social de los valores humanos: Desarrollos teóricos, metodológicos y aplicados (pp. 27-51).

Madri: Biblioteca Nueva.

ROKEACH, M. (1973). The nature of human values. New York: The Free Press.

SCHWARTZ, S. H. (1994). Are there universal aspects in the structure and contents of human values? Journal of Social Issues, 50, 19-45.

STEFANE, J.M.J. A enfermagem, o crescimento e desenvolvimento infantil.In: SHIMITZ, E.M.R.

A enfermagem em pediatria e puericultura. São Paulo: Atheneu, 2000.

UNICEF (Fundo das Nações Unidas para a Infância), 1998. Situação Mundial da Infância - A Nutrição em Foco. Brasília: UNICEF.

UNICEF (Fundo das Nações Unidas para a Infância), 1979. Cuidados Primários de Saúde - Relatório da

Conferência Internacional sobre Cuidados Primários de Saúde - Alma-Ata, 1978. Brasília: UNICEF.

Sobre os autores:

(1) Maria do Socorro de Andrade Reis é Pós-Graduada em psicologia Aplicada à Educação pela Universidade Regional do Cariri - URCA. E-mail: socorro.and@hotmail.com.

(2) Gislene Farias de |Oliveira é Psicóloga, Doutora em Psicologia Social. Professora Adjunta da Universidade Regional do Cariri - URCA e da Universidade Federal do Ceará UFC.

E-mail: gislenefarias@gmail.com.

Como citar este artigo (Formato ISO):

REIS, M.S.A.; OLIVEIRA, G.F. Valores Humanos em uma instituição educacional pública. Id on Line Revista de Psicologia, Julho de 2011, vol., n.14, p.50-61. ISSN 1981-1189. 